\title{
A INTRODUÇÃO DA FANTASIA NA METAPSICOLOGIA FREUDIANA: A REALIZAÇÃO ALUCINATÓRIA DE DESEJO E O SIGNO DE REALIDADE
}

\author{
The introduction of the fantasy \\ at Freud's metapsychology: \\ the hallucinatory's realization of desire \\ and the sign of reality
}

Clovis Eduardo Zanetti ${ }^{1}$

Resumo

O artigo visa a uma análise introdutória da recepção teórica da fantasia na obra de Freud exposta na correspondência a Fliess de 21 de setembro de 1897. Desdobra as teses implícitas na afirmação de que a fantasia faz saber que no inconscien te não existe signo de realidade de modo que não se pode distinguir en tre verda de e ficção. Localiza e circunscreve a problemática original em que esta afirmação se situa em relação à teoria do aparelho psíquico desenvolvida no texto "Projeto de uma psicologia" (1895). A referência de Freud às articulações deste texto permite sustentar a hipótese de que a fantasia encontra seus antecedentes teóricos e constitucionais na indistinção originária entre percepção e recordação presente nas realizações alucinatórias de desejo, e na compreensão do lugar e função desempenhada pelo signo de realidade neste primeiro momento da constituição psíquica humana.

Palavras-chave: Aparelho psíquico; Alucinação; Signo de realidade; Fantasia.

1 Mestrando pelo PPG em Filosofia da Universidade Federal de São Carlos (UFSCar), bolsista CNPq, sob orientação do Prof. Richard Theisen Simanke. Universidade Federal de São Carlos, Centro de Educação e Ciências Humanas - UFSCar Rodovia Washington Luís, km 235 Monjolinho - São Carlos 13565-905, SP - Brasil.

E-mail: br"zttceduardo@yahoo.com.br

Revista de Filosofia, Curitiba, v. 17 n.20, p. 25-43, jan./jun. 2005. 


\section{Abstract}

The article seek a introductory analysis of the theorical reception of the fantasy at Freud's work exposure at correspondence to Fliess at 21 of September, 1897. Unfold the implicit thesis at the affirmation that the fantasy do know that in the inconscious there isn'tsign of reality, so that it can't distinguish between true and fiction. Locate and circumscribe the original problematic in which this affirmation situated regarding to theory of psychic apparatus developed on the text " Project of a Psychology" (1895). The reference of Freud to the articulations of this text allow to sustain the hypothesis that the fantasy find your theorical and constitutional record in the originary indistinction between perception and memory presenting at hallucinatory's realization of desire, and at the understanding of the place and function performed for the sign of reality in this first moment of the human psychic constitution.

Keywords: Psychic apparatus; Hallucination; Reality sign; Fantasy.

\section{Introdução ao problema}

O conceito de fantasia foi sendo introduzido no corpo teórico da psicanálise mediante uma série de evidências clínicas que, ao se articularem ao conjunto das hipóteses metapsicológicas, conduziram a um problemático, porém fecundo, remanejamento teórico-clínico. Este momento negativo na história da psicanálise descrito nas correspondências de Freud a Fliess, mais especificamente na carta de 21 de setembro de 1897, colocou em questão um dos pontos mais visados por Freud neste período, que fora a realidade atribuída às cenas de sedução realizadas na infância que se encontravam invariavelmente nas recordações histéricas subjacentes à formação dos sintomas neuróticos (LAPLANCHE, 1895, p. 40).

A hipótese central, avançada no trabalho anterior em colaboração com Breuer Estudos sobre histeria (1893-1895), de que a causa das neuroses repousava na existência e na eficácia deste fator ativo desempenhado por representações afetivas in susceptíveis de consciên cia relacionadas ao conteúdo destas cenas, no que diz respeito às evidências clínicas, se manteve inabalável. Já sua fundamentação metapsicológica precisou em alguns pontos ser revista, pois se tomou um problema para a justificação teórica da existência e eficácia destas cenas inconscientes, a constatação, por parte de Freud, de que não era possível sustentar uma

Revista de Filosofia, Curitiba, v. 17 n.20, p. 25-43, jan./jun. 2005. 
referência predominantemente externa e contingente na origem e na constituição destas representações, e tampouco em sustentar a idéia correlata a esta da inexistência de uma sexualidade infantil. Tendo que dar conta, a partir disto, das evidências do lugar e da importância da intervenção das fantasias nestes processos internos ao aparelho que transcorrem entre a memória e a realidade na formação dos sintomas.

Neste deslocamento de eficácia, das reminiscências traumáticas para as fantasias na causação das neuroses, Freud relaciona nesta carta a Fliess (1897) a série de motivos que o levaram ao descrédito de sua teoria, e na seqüência apresenta a primeira conclusão metapsicológica advinda deste exame crítico relacionado à rememoração na análise clínica das neuroses, que fora: "o conhecimento seguro de que no inconsciente não existe um signo de realidade, de modo que não se pode distinguir entre a verdade e a ficção que foram investidas pelo afeto" (FREUD, 1988a, p. 301).

A referência de Freud à ausência deste signo de realidade marca um momento decisivo para a introdução da problemática das fantasias nas formulações metapsicológicas. Aí estamos diante de uma idéia mestra da teoria freudiana: não encontramos, no inconsciente, nen hum "ín dice de realida de" que permita distinguir a recordação "real" da pura e simples imagina ção. (LAPLANCHE, 1985, p. 39). Porém, esta referência ao signo de realidade somente pode ser devidamente compreendida se remetida ao texto de 1895, Projeto de uma psicologia, publicado em 1950, dez anos após a morte de seu autor._Neste trabalho, que antecede em aproximadamente dois anos este exame crítico, o signo de realidade aparece principalmente em dois momentos da constituição do aparelho psíquico: o primeiro relacionado à distinção entre recordação e percepção, e o segundo, na relação entre os processos do pensamento e sua articulação com a associação lingüística.

Este artigo que pretende realizar uma etapa preliminar de uma investigação se ocupará do primeiro momento da introdução deste conceito, onde se dá o estabelecimento de um critério eficiente para a distinção entre recordação e percepção, condição necessária para a passagem de um processo primário, automático e alucinatório, para os rudimentos de um processamento secundário voltado para a observação das condições externas ao aparelho. Neste sentido este trabalho tem por objetivo situar, tendo como base unicamente as formulações do Projeto... (1895), o lugar e o sentido da função desempe-

Revista de Filosofia, Curitiba, v. 17 n.20, p. 25-43, jan./jun. 2005. 
nhada por este signo de realidade nas origens do aparelho, e estabelecer, a partir daí, um ponto de partida para futuras investigações que permitam dizer, sob estas bases:

a) quais os possíveis argumentos metapsicológicos que sustentam a afirmação de Freud, diante das evidências clínicas da presença das fantasias na formação dos sintomas, de que no inconsciente não existe signo de realidade;

b) por que e como isto implica, em plena vigília, na vigência dos processos secundários, a impossibilidade do aparelho em distinguir verdade e ficção;

c) qual o alcance destes argumentos iniciais para o estabelecimento de um estatuto metapsicológico para a fantasia que nos próximos anos serão recebidas como produções psíquicas de pleno direito.

\section{A constituição do aparelho}

O signo de realidade é concebido no texto Projeto de uma psicologia em decorrência da introdução de um terceiro sistema na teoria do aparelho neuronal, o ômega. Este sistema é concebido ao lado dos dois outros já estabelecidos, o da memória psi e o da percepção phi. Ômega se torna necessário no momento em que os dois principais postulados para a construção de uma psicologia científica naturalista, o da quantidade $\mathrm{Q}$ e do neurônio $\mathrm{N}$, encontram seus limites em dar conta de explicar a característica qualitativa atribuída à consciência, que então passará a ser atribuída as operações deste novo sistema.

A modalidade de funcionamento que antecede a introdução da consciência na constituição do aparelho é regida por uma lei que Freud empresta da física newtoniana e que traduz de forma adequada sua hipótese sobre o movimento neurônico, que é a lei de inércia, um princípio de funcionamento que dita que toda célula nervosa aspira a libertarse de Q. (FREUD, 2003, p.176). O que significa que toda quantidade de excitação Q recebida pelo aparelho é descarregada automaticamente pela via motora, ou seja, este processamento da quantidade visa através de uma ação puramente reflexa, orientada no sentido sensório-motor, reconduzir todo o aumento da tensão interna a $\mathrm{Q}=0$.

Revista de Filosofia, Curitiba, v. 17 n.20, p. 25-43, jan./jun. 2005. 
A hipótese de um aparelho como este, regido exclusivamente pelo princípio de inércia cuja única fonte de excitação provém da estimulação externa, desempenha a função de uma ficção teórica, que permite, segundo Freud: 1. em continuidade com os dois postulados principais da quantidade em fluxo e a ocupação dos neurônios, compreender a arquitetura, desenvolvimento e desempenhos de seus sistemas; 2 . organizar e dar inteligibilidade a uma série de fenômenos observados na clínica das neuroses (FREUD, 2003, p.176).

De acordo com esta hipótese inicial, sua adequação a um organismo vivo exige uma série de substituições, pois a manutenção da vida implica que se leve em conta uma segunda fonte de excitação acrescida desde as necessidades vitais, uma fonte de excitação interna ao organismo, Freud diz das grandes urgências da vida: a fome, a respiração e a sexualidade. No caso destas necessidades a fuga de estímulos por meio da resposta reflexa é completamente ineficaz, e sua resolução exige a substituição da ação reflexa automática por uma ação específica dirigida ao mundo externo no sentido de obter o aprovisionamento dos objetos necessários à resolução da tensão.

Esta inclusão também exige uma modificação significativa na tendência à inércia, uma vez que sob este regime o aparelho é incapaz de tolerar qualquer acréscimo de excitação, o que é inconcebível para um organismo vivo. Neste sentido, o princípio de inércia é substituído pelo que Freud denomina princípio de constância, que exige que 0 aparelho seja capaz de tolerar um mínimo de acúmulo de excitação em seus sistemas, uma cota de energia necessária para iniciar os rudimentos de uma ação específica.

De início, segundo a experiência, o vivente não tem meios para realizar de modo eficiente esta ação no mundo que visa a satisfação das necessidades vitais a sua sobrevivência; sua ação frente às urgências é basicamente reflexa, como o grito, o choro, a agitação motora etc., que é uma via de eliminação, porém neste caso não resulta em alívio, pois o estímulo desde as fontes endógenas continua agindo de maneira constante e progressiva. No entanto, este ponto de partida reflexo abre 0 caminho que levará à alteração interna adequada ao cancelamento do estímulo, uma vez que ele adquire uma função secundária fundamental nesta vivência, que é a comunicação entre o vivente em desamparo e o agente prestativo que realiza a ação específica, o aprovisionamento do alimento. A inclusão necessária de um outro prestativo nestes desempe-

Revista de Filosofia, Curitiba, v. 17 n.20, p. 25-43, jan./jun. 2005. 
nhos vitais traz amplas conseqüências para o desenvolvimento psíquico, e o conjunto destas operações constituem o que Freud chama de vivência de satisfação.

Esta nova modalidade de funcionamento regida pelo princípio de constância mantém a mesma orientação de eliminação sensório-motora estabelecida pela tendência à inércia, a diferença está em que a quantidade (tensão) gerada pelo estímulo não é mais complemente eliminada, uma parcela fica retida nos neurônios sendo utilizada nos desempenhos relacionados à busca de satisfação. Esta retenção implica, como iremos demonstrar a seguir, a capacidade para a memória, uma função psíquica fundamental que se encontra completamente ausente sob a vigência do princípio de inércia, que requer, para o desempenho da ação reflexa, apenas a percepção.

Até este momento foi possível acompanhar as repercussões produzidas pela consideração das fontes internas de excitação na teoria do aparelho psíquico , o que marca a passagem de uma ficção teórica de um aparelho regido pela inércia para uma especulação sobre as origens do aparelho psíquico a partir de suas vivências fundamentais de dor e de satisfação, até chegar, em seu desenvolvimento mais completo e organizado, à constituição da consciência, como veremos adiante.

\section{Memória e percepção}

Freud, neste texto, concebe a memória, assim como a percepção, por meio da ação da quantidade sobre os neurônios. A hipótese é de que a ação da quantidade se dá de modo diferente nos sistemas phi e psi. Do ponto de vista evolutivo, os neurônios phi da percepção estão submetidos a uma quantidade muito mais intensa do que aquelas advindas do interior do corpo, o que faz com que as barreiras de contato entre seus neurônios estejam completamente permeáveis ao curso da quantidade, enquanto as barreiras de contato dos neurônios em psi, por sua localização tópica mais interna distantes da ação direta dos estímulos, manteriam uma certa impermeabilidade (resistência) ao curso da quantidade. Com isto se constituem duas classes de neurônios:

Revista de Filosofia, Curitiba, v. 17 n.20, p. 25-43, jan./jun. 2005. 
[(1.)] Os que deixam passar Qn' como se não tivessem barreiras de contato e que, portanto, após cada curso excitativo, estão no mesmo estado que antes; [(2.)] Os \{neurônios\}, cujas barreiras de contato se fazem valer ... que podem, após cada excitação, estar em outro estado do que 0 anterior ... [estes são os neurônios] portadores da memória e assim, provavelmente, dos processos psíquicos em geral (FREUD, 2003, p.179).

O curso da quantidade proveniente das fontes endógenas de excitação, após atingir um certo limiar, ultrapassa a resistência existente entre o aparelho e o interior do corpo. Ao ultrapassar esta resistência oferecida pelas barreiras de contato entre os neurônios, o curso da quantidade abre trilhas nestas barreiras que Freud denomina facilitações. $\mathrm{Na}$ próxima recorrência da corrente excitatória, esta é induzida a percorrer novamente esta trilha já facilitada. Esta é a base material dinâmica da memória - uma representação - que é composta em sua forma mais elementar de um neurônio mais uma facilitação, e em sua forma mais complexa constitui uma multiplicidade de processos associativos (SIMANKE, 2004a). No caso da recorrência do curso psíquico por estas trilhas facilitadas entre os neurônios devido à ação da quantidade de origem somática, trata-se, então, da constituição de representações mnêmicas das excitações provenientes do interior do corpo.

Após o curso da quantidade por estes circuitos facilitados, a corrente excitatória deixa um certo resíduo mínimo de quantidade que fica retido nestes neurônios, o que é explicado pela retomada da resistência das barreiras de contato após a passagem da excitação impedindo que este resíduo seja eliminado, constituindo deste modo um grupo de neurônios psi permanentemente ocupados. Portanto, a hipótese necessária da constância está internamente articulada com: a constituição do sistema psi da memória; com a representação das excitações somáticas no interior do aparelho neuronal e com a formação deste grupo de neurônios ligados em psi.

Existem também as representações mnêmicas provenientes da percepção phi, constituídas pela ação da quantidade externa sob o aparelho. Nestas representações provenientes da percepção, a dor desempenha um fator preponderante. O curso da quantidade de origem externa em ação no fenômeno da dor, por ser de grande intensidade, deixa atrás de si poderosas facilitações em direção à representação do objeto hostil, e estas funcionam como motivos compulsivos no interior de psi.

Revista de Filosofia, Curitiba, v. 17 n.20, p. 25-43, jan./jun. 2005. 
Com estas considerações, Freud toca o limite do que é possível deduzir e explicar a partir da articulação entre os postulados principais da quantidade e do neurônio na sua intenção de construir uma psicologia científica naturalista. O limite desta construção é colocado pela impossibilidade de se conceber a consciência unicamente pela ação da quantidade, para tanto é preciso incluir a qualidade e as sensações. Até este momento da estruturação do aparelho, tanto as atividades quanto à própria constituição da memória, a base de todos os processos psíquicos, prescindiram completamente das funções desempenhadas pela consciência.

\section{Qualidade e consciência}

Dado a construção anterior, é necessário indicar a localização tópica da origem da qualidade, Freud descarta três possibilidades para esta origem: ela não pode estar no mundo externo que em sua orientação fisicalista é composto apenas de massas em movimento. Não pode se dar no sistema phi da percepção dado o pressuposto de que a consciência esteja localizada em níveis superiores de organização do funcionamento psíquico, e por último não pode estar no sistema psi, pois seus processos psíquicos, o recordar e reproduzir são, por natureza, sem qualidade.

Diante destas dificuldades, Freud se vê obrigado a postular a existência de um terceiro sistema, o ômega, que dê conta de explicar a origem e as operações que envolvem as sensações conscientes de qualidade. Esta hipótese, apesar de ser requerida pelo desenvolvimento precedente, não decorre das noções anteriormente apresentadas, não pode ser deduzida dos princípios assumidos desde o início (SIMANKE, 2004b, p.138). Freud também não consegue estabelecer a origem evolutiva deste sistema, que é introduzido mais como uma ficção que poderá ser útil até o momento em que se possa encontrar uma hipótese mais adequada a sua construção.

O problema passa a ser quais as operações necessárias para que o aparelho neuronal seja capaz de consciência, ou seja, como é possível ao aparelho operar uma transformação que partindo da quantidade resulte, ao final de um processo dinâmico, em qualidade; o sistema ômega seria capaz deste desempenho. Para tanto é necessário que este

Revista de Filosofia, Curitiba, v. 17 n.20, p. 25-43, jan./jun. 2005. 
sistema estabeleça dois modos diferentes de relação aos outros: um por meio da quantidade e outro pela da apreensão da propriedade temporal gerada pelo curso da quantidade, o período. Com esta hipótese do período transmitido juntamente com a quantidade é preciso mostrar que, embora esta não possa ser plenamente derivada das proposições anteriores, não está em desacordo com elas, nem contradiz as idéias até agora aceitas e, em princípio, demonstradas (SIMANKE, 2004b, p.140).

Dada a localização de ômega ser a mais interna e afastada da periferia sensorial ( phi - psi - ômega), a quantidade a que está submetido é mínima, pois já vem fracionada pela passagem pelos crivos protetores dos órgãos sensoriais, pelo sistema phi e pelo sistema psi. De acordo com esta distribuição, Freud propõe então que as sensações conscientes sejam produzidas apenas ali onde as quantidades estão reduzidas ao máximo (FREUD, 2003, p.188).

Ao lado desta questão tópica e econômica é preciso responder a questão das propriedades destes períodos. Os períodos seriam os aspectos formais que acompanham o movimento, uma propriedade dos estímulos como as diferenças de freqüência e oscilação que chegam a percepção com um amplo e diverso grau de variações. O sistema psi por sua vez também possui um período próprio ao curso da quantidade durante seus processos, porém seu período é monótono. A divergência entre as variações dos períodos provenientes da percepção e a monotonia característica do período em psi permite avançar mais uma hipótese, que é a seguinte: as divergências, segundo este período psíquico próprio, chegam à consciên cia como qualidades (FREUD, 2003, p.189). Estas diferenças de período também se explicam pela ação protetora dos crivos dos órgãos sensoriais que apenas permitem a passagem de determinados processos com certos períodos. Selecionadas estas propriedades temporais, elas são transmitidas da periferia para o centro, até chegar a ômega, onde produzem sensações conscientes de qualidades.

A propagação do período não está submetida às resistências das barreiras de contato entre os neurônios, estas funcionam apenas para o curso da quantidade, portanto sua circulação é livre entre os sistemas, no entanto, esta total permeabilidade entre os neurônios quanto ao período exclui a possibilidade de que haja, por esta via, uma memória destas sensações qualitativas que são a base material e o fundamento da consciência perceptiva. É bastante evidente que a natureza desta transformação da divergência dos períodos para produção de cons-

Revista de Filosofia, Curitiba, v. 17 n.20, p. 25-43, jan./jun. 2005. 
ciência permanece enigmática. Com esta concepção, Freud obtém apenas as condições de possibilidade da consciência, mas não a elucidação do mecanismo ou da natureza da consciência ela mesma, este seria um limite interno da metapsicologia freudiana (SIMANKE, 2004b, p.128).

A ocupação dos neurônios em ômega pela quantidade advinda de psi, apesar de ser mínima, também incita a descarga de excitação, esta possibilidade de ocupação gera uma segunda série de sensações: a de prazer e desprazer. Esta série proporciona uma mediação entre os processos em psi e a consciência. O desprazer seria então a sensação consciente que acompanha a ocupação dos neurônios ômega, e o prazer corresponderia a sensação consciente de sua eliminação, ou seja, são sensações que resultam do nível da quantidade neste sistema, muito diferentes da série qualitativa relacionada à presença dos objetos na percepção que acompanha a propagação do período.

Neste ponto Freud faz uma consideração importante sobre as conseqüências do entrecruzamento destas duas séries de sensações no interior de ômega, uma advinda da propagação do período e outra da quantidade, que é a seguinte: a condição para que este sistema permaneça receptivo aos períodos da percepção é que a ocupação de seus neurônios esteja num nível ótimo, que não exceda ou não caia abaixo de um certo limiar. Isto significa que com presença das sensações de prazer e desprazer que indicam esta oscilação de nível "desaparece a aptidão para perceber qualidades sensoriais, que, por assim dizer, situam-se numa zona de indiferença entre prazer e desprazer."(FREUD, 2003, p.191). O que está plenamente de acordo com a experiência, pois como é possível observar, o sistema da percepção fica temporariamente inoperante no caso de um sofrimento psíquico muito intenso (ansiedade, desespero etc.) ou de uma experiência prazerosa muito vívida cujo protótipo seria o orgasmo sexual, por exemplo (SIMANKE, 2004b, p.173).

\section{As vivências fundamentais}

Com as primeiras vivên cias de satisfação e de dor ocorrem processos dinâmicos significativos no interior de psi. A satisfação das necessidades vitais e a ocorrência da dor física submetem o sistema da memória a duas diferentes fontes de quantidade, esta duplicidade de origens repercute na divisão de psi em dois grupos de neurônios: os neurônios

Revista de Filosofia, Curitiba, v. 17 n.20, p. 25-43, jan./jun. 2005. 
do manto ocupados desde a fonte externa pela percepção e neurônios do núcleo ocupados desde as conduções endógenas. Há uma particularidade importante em relação à estimulação endógena, diferente da exógena, que age de modo intermitente e por impactos incidindo sobre a proteção dos aparelhos de terminações nervosas, o estímulo endógeno age por somação, sua excitação é contínua, e seus impulsos têm uma condução direta e facilitada até o núcleo de psi. Nesta via não há proteções, e uma vez que a condução alcance um nível suficiente para ultrapassar a resistência entre o aparelho psíquico e o interior do corpo ocupando assim os neurônios do núcleo, o aparelho é tomado um impulso que, segundo Freud, é o responsável por todo o desenvolvimento psíquico.

A eliminação da quantidade devido à experiência de satisfação se traduz em ômega numa sensação consciente de prazer, ao que segue o restabelecimento da resistência entre o núcleo de psi e o interior do organismo, cessando o estímulo. Esta experiência também deixa no manto de psi uma imagem mnêmica da percepção do objeto que trouxe a satisfação: a pessoa prestativa; e por último, são registrados nos neurônios do manto de psi mensagens de eliminação ocasionadas em várias partes do corpo decorrentes do movimento reflexo que segue a ação específica, formando neste uma imagem mnêmica motora desta vivência.

A experiência representada pela totalidade destes eventos põe os três sistemas que compõem o aparelho a trabalhar em conjunto, compondo uma rede de processos dinâmicos associativos entre as imagens mnêmicas do objeto, as imagens da eliminação motora e as imagens mnêmicas das excitações somática e o interior do corpo. Estas vias facilitadas entre os neurônios, o corpo e o mundo são indeléveis; a vivência fixa um caminho associativo de eliminação e com o reaparecimento da incitação e do estado de desejo o curso da quantidade tende a percorrer estas vias facilitadas ocupando intensamente suas representações. Esta compulsão em percorrer sempre este mesmo circuito de facilitações Freud chama de atração desiderativa primária. Toda vez que o curso intenso da corrente psíquica for dirigido pela atração primária em direção a recordação do objeto, haverá a produção pelo aparelho de uma animação de desejo que resulta "em primeiro lugar no mesmo que a percepção, ou seja, em alucinação. Se em conseqüência disso a ação reflexa for iniciada, não há como não faltar desilusão" (FREUD, 2003, p.197).

Revista de Filosofia, Curitiba, v. 17 n.20, p. 25-43, jan./jun. 2005. 
Algo similar acontece com a vivência dolorosa. Em um segundo momento, com a ocorrência de uma percepção que remeta por algum elo associativo as representações da cena dolorosa, a quantidade gerada por esta recordação percorre as vias facilitadas pela primeira ocorrência em direção a ocupação da imagem recordativa do objeto, o que é acompanhado de grande desprazer e de uma forte inclinação à eliminação. Esta forte inclinação leva o nome de defesa primária ou repressão, que designa o motivo compulsivo que advém da repulsa em manter ocupada a representação do objeto hostil.

\section{$\mathrm{O}$ afeto e o desejo}

O que há de semelhante entre as duas vivências é que ambas deixam dois restos ativos no interior do sistema psi, que são: o afeto e 0 desejo. Estes restos são capazes por si mesmos de mobilizarem grandes quantidades desde o interior do aparelho sem que haja uma referência direta à presença dos objetos na percepção, pois como foi possível demonstrar, a compulsão exercida pela atração desiderativa esta voltada primariamente para imagem recordativa do objeto, e não para sua presença efetiva na percepção. O mesmo se passa com a defesa primária que é a repulsa em ocupar a imagem recordativa do objeto hostil. Deste modo, a animação destes processos mnêmicos dá lugar no aparelho psíquico a reprodução alucinatória da vivência de satisfação, e a reprodução no afeto da vivência traumática, e estes fenômenos, tão próximos da experiência psicológica e da observação, podem ser tomados como índices seguros da existência e da eficácia da memória psíquica na teoria do aparelho, que é definida por Freud como "o poder de efetividade contínua de uma vivência" (FREUD, 2003, p. 180).

A animação destes processos reprodutivos que no limite levam até a alucinação passam a representar a presença da atividade de processos primários em psi. Processos que mobilizam intensas somas de excitação em livre curso, cuja principal característica resulta na impossibilidade do aparelho em diferenciar percepção e recordação, que é o que indica o fenômeno alucinatório. Como já foi demonstrado anteriormente, esta diferenciação está parcialmente comprometida devido a um problema colocado pela localização tópica dos sistemas (phi - psi - ômega), pois o sistema ômega, o mais afastado da periferia sensorial, responsável

Revista de Filosofia, Curitiba, v. 17 n.20, p. 25-43, jan./jun. 2005. 
pela consciência qualitativa e pelas sensações conscientes de prazer e desprazer, recebe o curso da quantidade de psi, e por esta via quantitativa não tem relações diretas com a percepção. Portanto, não tem como diferenciar a fonte da quantidade que lhe chega, se advém do sistema phi ou se decorre do próprio sistema psi, o que explica a origem estrutural desta indistinção primária entre percepção e recordação. Também é importante lembrar que a intensidade das sensações de prazer e desprazer torna o sistema da percepção temporariamente inoperante. Assim, originariamente o aparelho psíquico se encontra submetido de maneira compulsória à força da ação psíquica da recordação, e é somente a posteriori, e por aprendizagem, que a percepção adquire uma relativa autonomia e importância frente à memória, isto na medida em que as necessidades da vida impõem a observância das condições externas ao aparelho psíquico (GABBI JR, 2003, p.65).

Tudo indica que o critério para acertar esta diferença não é dado a priori, e também tem de vir de outra fonte. Sua importância para a manutenção da atividade psíquica se encontra no fato de que com esta indistinção primária o aparelho sofre repetidas vezes dano e desamparo devido ao fracasso em obter a satisfação efetiva de suas necessidades vitais pela via alucinatória. Por outro lado, também existe a necessidade de um signo advindo de algum lugar que possa evitar em tempo o desencadeamento da defesa primária excessiva pela ocupação da imagem recordativa do objeto hostil.

Os repetidos fracassos em se obter satisfação efetiva pela via alucinatória incitam no interior de psi a uma organização que visa a dar conta de superar esta via reflexa, evitando o desprazer e os gastos excessivos com a defesa primária. Esta organização que tem por base a totalidade das facilitações entre os neurônios deste sistema, Freud denomina eu. Os neurônios que compõem estes processos do eu organizados no interior de psi se encontram permanentemente ocupados, isto devido sua relação direta com o interior do corpo e a recepção constante das quantidades endógenas. A função desta organização, que não deve ser confundida com a consciência, passa a ser a de inibir o desenvolvimento de processos associativos primários através de ocupações laterais. Estas ocupações desviam o curso excitatório do caminho que levaria a animação alucinatória de desejo ou a defesa primária. O que constitui a primeira condição necessária, mas não suficiente, para criação de um signo que possa indicar uma diferença entre percepção e recordação.

Revista de Filosofia, Curitiba, v. 17 n.20, p. 25-43, jan./jun. 2005. 


\section{O signo de realidade}

A hipótese de Freud é que este signo pode ser fornecido pelo sistema ômega, e ele o chama de: signo de realidade. A excitação ou ocupação dos neurônios deste sistema produz fundamentalmente sensações, e esta nova produção, o signo de realidade não foge a regra, também deve ser revestido de alguma qualidade, é preciso saber como e a partir de que estes são produzidos. A percepção guarda uma relação direta e indireta com o sistema ômega, direta pela propagação do período, indireta pelo curso da quantidade. A excitação qualitativa em ômega pelos períodos da percepção gera também uma eliminação que chega até a psi como uma mensagem. Esta mensagem de eliminação em ômega, segundo Freud, constitui um signo qualitativo ou de realidade para 0 aparelho, pois indica por sensações a presença efetiva de objetos na percepção. Assim a descarga de excitação por esse sistema seria um meio de acesso aos objetos, um signo da existência real e objetiva do mundo externo pela mediação das sensações. No entanto, na seqüência Freud reconhece um problema para a eficácia deste signo, que é o seguinte:

se o objeto desiderativo for ocupado com abundância, de modo a ser animado alucinatoriamente, também resulta o mesmo signo de eliminação ou de realidade que na percepção externa. $O$ critério falha neste caso (FREUD, 2003, p.203).

Esta afirmação de Freud reúne os principais elementos do problema em questão e expõe de maneira inequívoca seu núcleo por meio do reconhecimento de uma falha na mediação do aparelho com o mundo, mais especificamente, com uma parte do mundo, aquela que interessa a resolução de suas urgências vitais, o objeto desiderativo. Este objeto, como vimos, após a vivência de satisfação, constituiu-se para o aparelho também como uma representação, e se esta representação, diante do estado de desejo, for ocupada com abundância, como é característico do curso da energia livre no processo primário, dá lugar a uma animação alucinatória. O problema que Freud está apresentando é que esta animação alucinatória também resulta no mesmo signo de eliminação ou de realidade que aqueles emitidos para a percepção externa, ou seja, a alucinação do objeto de desejo também acompanha as mesmas sensa-

Revista de Filosofia, Curitiba, v. 17 n.20, p. 25-43, jan./jun. 2005. 
ções que são geradas quando da presença efetiva do objeto para a percepção externa. Logo, a mediação pelas sensações deixa de ser um meio de atestar a existência real de objetos externos, para se tornar justamente o oposto, o meio pelo qual a diferença entre recordação e percepção se apaga. $\mathrm{O}$ aparelho psíquico, submetido às urgências da vida e à intensa excitação de suas próprias recordações relacionadas à experiência de satisfação, às toma inevitavelmente como se tratassem de uma percepção. A conseqüência deste erro é que os movimentos de sucção são realizados na ausência do objeto, o seio, o que aumenta o desprazer, e como Freud diz, aí não há como faltar à desilusão.

Para entender esta falha na base dos processos psíquicos é preciso conceber que a eliminação ômega, cuja mensagem constitui o signo de realidade, possa ser obtida tanto por meio da propagação do período desde a percepção, quanto da ocupação direta pela quantidade desde a memória. Se isso não é de todo contraditório, pode ser bem fecundo, pois permite a seguinte questão: que realidade é esta que o signo indica justamente quando falha em distinguir recordação e percepção? Freud não faz esta pergunta neste momento, mas há indicações de que a questão começa a se impor, e parece não ser nada abusivo formular a seguinte hipótese: se sob a vigência dos processos primários é produzido o mesmo signo de eliminação ou de realidade que é produzido para a percepção, e se sua função é indicar uma realidade, este signo pode ser pensado, quando emitido diante da animação alucinatória, como signo de realidade psíquica, ou seja, uma mensagem qualitativa, índice da existência e da eficácia da força psíquica do desejo no momento em que esta incide sob os circuitos representacionais que compõem a memória psíquica. Memória cujos processos dinâmicos associativos são o fundamento de toda esta reprodução e que parece ter a consistência de uma realidade para o aparelho.

A seguir Freud finalmente encontra uma solução para o estabelecimento de um critério eficiente para a distinção em jogo, reconhecendo uma condição para que o signo de realidade seja emitido somente junto às sensações produzidas pela presença de objetos na percepção. A condição é que a ocupação das imagens recordativas dos objetos do desejo seja inibida pelo eu, ou seja, os processos do eu, por meio das ocupações laterais, seriam responsáveis por impedir que o curso psíquico, sob a intensa animação do desejo, siga diretamente para a representação de objeto, e resulte com isso em um signo qualitativo. Deste modo,

Revista de Filosofia, Curitiba, v. 17 n.20, p. 25-43, jan./jun. 2005. 
é a inibição do eu que dá às condições para que o critério funcione e haja uma via de distinção entre percepção e recordação. Com a animação reprodutiva do desejo sob inibição a intensidade das quantidades advindas da percepção da realidade externa é aumentada, mantendo a atenção psíquica voltada para as condições externas ao aparelho mediante a ocupação dos signos de qualidade.

A instituição desta inibição psíquica da realização alucinatória do desejo por parte do eu, neste contexto, funciona mais como uma defesa primária que possibilita um retardo da descarga reflexa automática por meio da ação motora, uma espera, até que o signo de realidade, agora corretamente utilizado, indique a presença efetiva do objeto na percepção, momento em que, ocorrendo à eliminação motora, a satisfação é corada de êxito. Esta distinção entre alucinação e percepção é uma aquisição fundamental do funcionamento psíquico, ao que segue a possibilidade do desenvolvimento de uma série de funções superiores no interior do aparelho.

Este é o sentido e o lugar da função desempenhada pelo signo de realidade nas origens do aparelho, ele participa, juntamente com os desempenhos do eu, da substituição dos processos psíquicos primários pelos processos psíquicos secundários, que em termos econômicos equivale à passagem do princípio de inércia para a tendência a constância. Os processos secundários são todas as atividades psíquicas advindas sob a condição desta inibição psíquica do processo primário alucinatório. 0 reconhecer, o julgar, o recordar, o pensamento, a fala, são processos que começam a se organizar em função da necessidade vital de se observar às condições externas ao psiquismo, aí o recurso ao signo de realidade serve, a cada uma destas operações, como um elemento mediador entre o aparelho e o mundo, um mecanismo diferenciador e organizador da relação en tre interno e externo (GABBY JR, 2003, p.69).

\section{Considerações finais}

Com este trabalho, foi dado um passo preliminar, porém fundamental, para a resolução do problema a qual se propõe a tratar, qual seja, a análise introdutória da recepção teórica da fantasia em Freud. A pesquisa teve por objetivo situar a problemática original em que se insere a afirmação do autor de que a fantasia faz saber que no inconsciente

Revista de Filosofia, Curitiba, v. 17 n.20, p. 25-43, jan./jun. 2005. 
não existe signo de realidade de modo que não se pode distinguir entre verdade e ficção. Esta etapa preliminar se deteve em explicitar o sentido e o lugar ocupado pelo signo de realidade na teoria do aparelho desenvolvida no texto Projeto de uma psicologia (1895), e verificar com isso à importância da compreensão do signo de realidade para a problemática da fantasia, uma vez que a presença ou ausência deste signo incide precisamente nesta indistinção estrutural entre recordação e percepção, uma indistinção muito próxima daquela que Freud atribuirá a fantasia em 1897. Entender estes processos no interior da teoria do aparelho permitiu localizar os fundamentos que presidiram a recepção metapsicológica deste fenômeno clínico tão caro à psicanálise freudiana. Com base neste desenvolvimento, podemos concluir com a seguinte hipótese: foi precisamente a compreensão desta falha originária que dá lugar a esta impossibilidade de distinção que se observa na clínica da alucinação, mas também nos sonhos e nas fantasias de sedução, que permitiu a Freud, diante do abalo que sua clínica e teoria sofreram com a descoberta das fantasias, prosseguir no exame e no estabelecimento dos fundamentos da formação dos sintomas e da vida psíquica em geral.

\section{Notas}

Existem divergências sobre o valor deste escrito na obra de Freud, geralmente a literatura se divide em duas grandes posições: ou o texto é tido como um desvio neurológico na constituição da psicanálise, como é o caso da avaliação feita por autores como Garcia-Roza (2001, p.60) por exemplo, ou é tomado como já sendo uma teoria psicológica, onde o neurológico deve ser encarado apenas como metáfora da psicologia implícita nele, como se encontra em algumas leituras lacanianas. Em ambas as avaliações o valor e o lugar deste texto na composição da teoria freudiana é deslocado e reduzido. Existe em contrapartida uma terceira avaliação realizada por autores como Geerardyn (1997), Gabby Jr. (2003) e Simanke (2004 a,b) entre outros, que tende a localizar e explicitar lógica e historicamente, o lugar que este trabalho ocupa no desenvolvimento da teoria psicanalítica, os problemas que se propõem a resolver, e sua contribuição para o conjunto da obra. O presente artigo, que não tem como foco esta problemática em específico, tem como referência esta terceira via, e situa o Projeto... (1895) dentro da orienta-

Revista de Filosofia, Curitiba, v. 17 n.20, p. 25-43, jan./jun. 2005. 
ção científico-naturalista de Freud, onde é possível verificar que o campo das ciências naturais e a psicologia do inconsciente nunca foram alternativas excludentes para o autor.

Esta hipótese estaria plenamente de acordo com todo o desenvolvimento metapsicológico realizado até o momento; porém, é preciso lembrar que este texto Projeto de uma psicologia (1895) foi escrito, entre outras coisas, para justificar a teoria da sedu ção. Portanto, apesar das evidências da organização e da eficácia desta realidade psíquica, neste trabalho em que não há referência à fantasia, Freud precisa sustentar a predominância da realidade externa objetiva do atentado sexual como causa dos sintomas, que é o argumento que sustenta sua hipótese etiológica de que a histeria é adquirida e não uma degeneração hereditária. O paradoxal e talvez o mais interessante destes argumentos é justamente que nestas reproduções alucinatórias primárias, que formam a base do que mais adiante poderá se dizer sobre as fantasias, não é a realidade externa que está em ação e sim os restos ativos deixados pelas vivências.

* Trabalho apresentado no GT de Filosofia e Psicanálise durante o XI Encontro Nacional de Filosofia da ANPOF, de 18 a 22 de outubro de 2004, Salvador - Bahia.

\section{Referências}

FREUD, S. Fragmentos de la correspondencia con Fliess. Buenos Aires: Amorrotu, 1988a. (Obras Completas de Sigmund Freud, v.1).

. Estudios sobre la histeria. Buenos Aires: Amorrotu, 1988. (Obras Completas de Sigmund Freud, v. 2,).

. Projeto de uma psicologia científica. In: GABBI JUNIOR, O. F. Notas a projeto de uma psicologia: as origens utilitaristas da psicanálise. Trad. Osmyr Faria Gabbi Junior. Rio de Janeiro, RJ: Imago, 2003.

GARCIA-ROZA, L A. Freud e o inconsciente. Rio de Janeiro, RJ: Jorge Zahar, 2001. 
GABBI JUNIOR, O. F. Notas a projeto de uma psicologia: as origens utilitaristas da psicanálise: Rio de Janeiro, RJ: Imago, 2003.

GEERARDYN, F. Freud's Project: the roots of psychoanalysis. London: Rebus, 1997.

LAPLANCHE, J. Vida e morte em psicanálise. Porto Alegre: Artes Médicas, 1985.

SIMANKE, R T. Memória, afeto e representação: o lugar do Projeto no desenvolvimento inicial da metapsicologia freudiana. 2004a. (in press).

SIMANKE, R. T. Mente, cérebro e consciência nos primórdios da metapsicologia freudiana: uma análise do Projeto de uma psicologia (1895). 2004b. (in press).

Recebido em: Received in: 20/11/2004 Aprovado em: Approved in: 17/02/2005 